\title{
Hydrodynamic connectivity, water temperature, and salinity are major drivers of piscirickettsiosis prevalence and transmission among salmonid farms in Chile
}

\author{
F. Bravo ${ }^{1, *}$, J. P. S. Sidhu' ${ }^{2}$, P. Bernal ${ }^{1}$, R. H. Bustamante ${ }^{3}$, S. Condie ${ }^{4}$, B. Gorton ${ }^{4}$, \\ M. Herzfeld ${ }^{4}$, D. Jimenez ${ }^{5}$, F. O. Mardones ${ }^{6}$, F. Rizwi ${ }^{4}$, A. D. L. Steven ${ }^{3}$ \\ ${ }^{1}$ Fundación CSIRO Chile Research, Apoquindo 4700, Las Condes, Santiago, Chile \\ ${ }^{2}$ CSIRO Oceans and Atmosphere, Ecosciences Precinct, 41 Boggo Road, Dutton Park, QLD 4102, Australia \\ ${ }^{3}$ CSIRO Oceans and Atmosphere, Queensland BioSciences Precinct (QBP), 306 Carmody Rd, St Lucia, Brisbane, \\ QLD 4072, Australia \\ ${ }^{4}$ CSIRO Oceans and Atmosphere, GPO Box 1538, Hobart, TAS 7001, Australia \\ ${ }^{5}$ Instituto Tecnológico del Salmón, Av. Juan Soler Manfredini 41, OF 1802, Puerto Montt, Chile \\ ${ }^{6}$ Escuela Medicina Veterinaria, Pontificia Universidad Católica de Chile, Santiago, Chile
}

\begin{abstract}
Piscirickettsiosis is one of the most important diseases affecting farmed salmonid in Chile. Several studies have demonstrated the survival of Piscirickettsia salmonis in seawater and the horizontal transmission from infected to non-infected fish; however, the extent of waterborne transmission between farms has not been quantified. In this study, we used a stochastic hydrodynamic connectivity-based disease spread model to determine the role of hydrodynamic connectivity and the effect of seawater temperature and salinity on the dynamics of piscirickettsiosis in the Los Lagos region of Chile. Results demonstrate that environmental dynamics play a major role in disease prevalence. The strongest determinants of piscirickettsiosis prevalence were the number of infected farms in upstream waters and the extent of disease outbreaks in upstream waters (total mortality), followed by seawater salinity and temperature. In farms downstream from infected farms, observed disease prevalence $25 \mathrm{wk}$ into the farming cycle was close to $100 \%$, while in farms with little or no exposure to upstream, infected farms, prevalence reached only $\sim 10 \%$ by the end of the farming cycle (Week 56). No previous studies have quantified the scales of connectivity associated with piscirickettsiosis or provided risk metrics of waterborne transmission of the disease among farms; these are a novel aspect of this research. The above knowledge regarding the use of the epidemiological model will allow industry and regulators to better
\end{abstract}

*Corresponding author: bravofco@gmail.com

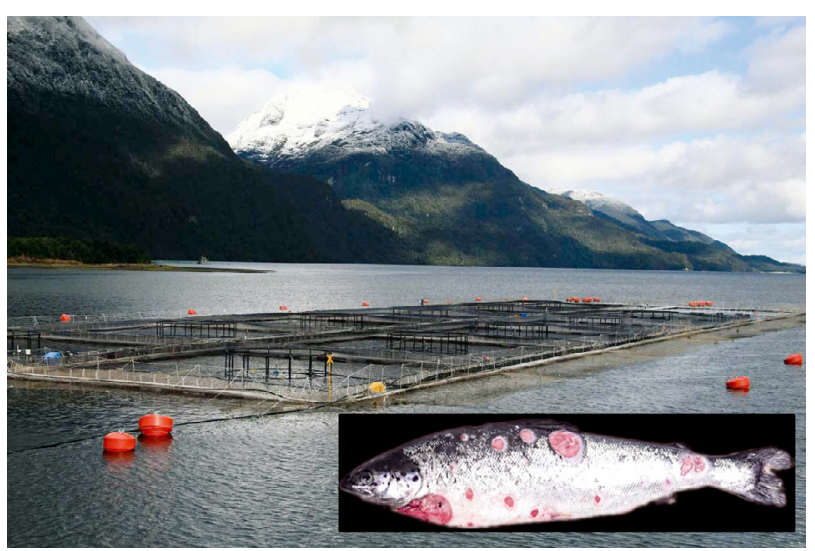

The pressure of infection of Piscirickettsia salmonis (inset) among farmed salmonid populations is controlled by oceanographic conditions including hydrodynamic connectivity, seawater temperature, and salinity.

Photo credits: Salmon Technological Institute (INTESAL) of SalmonChile and Marcos Godoy (inset)

target disease control strategies for more effective control of piscirickettsiosis in the study area.

KEY WORDS: Salmonid farming - Piscirickettsiosis · Epidemiology $\cdot$ Hydrodynamic connectivity $\cdot$ Seawater temperature $\cdot$ Salinity 


\section{INTRODUCTION}

Aquaculture of seawater salmonid species (hereinafter referred to as 'salmon') has expanded rapidly in the last 2 decades to become the second-largest in the world, with an annual production of over $900000 \mathrm{t}$ (SERNAPESCA 2018a). However, the rapid expansion in the number of marine farms and total salmonid biomass has coincided with an increased prevalence and severity of many diseases (Figueroa et al. 2019).

In Chile, one of the most devastating pathogens of farmed salmon is Piscirickettsia salmonis, a Gramnegative intracellular bacterium that causes salmonid rickettsial syndrome (SRS) or piscirickettsiosis. In salmon-farming countries in the Northern Hemisphere, such as Canada (Cusack et al. 2002) and Norway (Olsen et al. 1997), the prevalence of piscirickettsiosis is relatively low, whereas in Chile, it is a leading cause of mortality (Rozas \& Enriquez 2014, SERNAPESCA 2016, 2018b,c) and high use of antibiotics (Miranda et al. 2018). Estimates of economic losses due to $P$. salmonis infections since 1990 range between 10 million and 700 million USD annually (Cvitanich et al. 1995, Cabezas 2006, Rozas \& Enriquez 2014, Maisey et al. 2017).

The route of transmission of $P$. salmonis is not completely understood, although penetration of salmon skin and/or gills by $P$. salmonis has been reported to result in the onset of infection in experimental animals (Smith et al. 1999, 2004). Waterborne (horizontal) transmission of $P$. salmonis has also been demonstrated in the absence of parasites or vectors in coho salmon held in seawater and freshwater (Cvitanich et al. 1991). Prolonged survival (14-40 d) of the bacterium in seawater has also been reported in several studies (Lannan \& Fryer 1994, Olivares \& Marshall 2010). Waterborne transmission of $P$. salmonis from fish to fish within and across farms has therefore been recognized as the main route of infection (Almendras \& Fuentealba 1997, Fryer \& Hedrick 2003), but the extent of waterborne transmission between farms has, to date, not been quantified in Chile.

Currently, piscirickettsiosis prevention and control strategies include vaccination, antibiotics (i.e. florfenicol and oxytetracycline), and alternative treatments with immunomodulators and immunostimulants of variable effectiveness (Rivas-Aravena et al. 2013, Valenzuela et al. 2015). Piscirickettsiosis control strategies in Chile also include coordinated stocking and a fallowing period of 3 mo after harvesting under well-defined areas of coordinated management (SERNAPESCA 2008, 2009). Physical separation of farms or groups of farms is an important disease prevention and control mechanism in open net pens in marine aquaculture (Salama \& Murray 2013). A minimum safe distance among farms of 1 nautical mile (nmi) has been recommended in Chile. Furthermore, a surveillance zone of $5 \mathrm{nmi}$ around farms is also applied in the event of a disease outbreak (MINECOM 2002).

It is increasingly recognized that the emergence, prevalence, and severity of diseases is driven by complex pathogen-host and environment interactions (Callaway et al. 2012, Engering et al. 2013, Groner et al. 2016). Several risk factors, both biotic (age and species) and abiotic (water temperature, salinity, sunlight, hydrodynamic connectivity), along with farming practices (stocking date, fish density, vaccination, smolt quality) are known to contribute to the onset and progression of fish diseases (Lannan \& Fryer 1994, Murray 2013, Rees et al. 2014, Price et al. 2017, Estévez et al. 2019). To design effective disease prevention and management strategies, the complex and often fluid relationships among host-pathogen and environmental drivers of the disease need to be well understood (Mardones et al. 2018).

Over the years, significant effort has been devoted to the development of models for investigating the environmental transmission of pathogens within open-cage salmon aquaculture (Salama \& Rabe 2013). These models include compartmental infectious disease models, also known as SIRs (susceptibleinfectious-recovered) (Amundrud \& Murray 2009, Aldrin et al. 2011), hydrodynamic and particle tracking models coupled with network analysis techniques (Amundrud \& Murray 2009, Viljugrein et al. 2009, Salama et al. 2011, 2018, MODS 2012, Salama \& Rabe 2013, Stene et al. 2014b, Foreman et al. 2015a, Samsing et al. 2016, 2017), agent-based models (Alaliyat et al. 2019a), and statistical methods (Viljugrein et al. 2009, Rees et al. 2014, Stene et al. 2014b). The proximity to diseased farms has been recognized as a major risk factor for the onset of diseases such as infectious salmon anemia virus, salmon pancreas disease virus, hematopoietic necrosis virus, and piscirickettsiosis (Gustafson et al. 2007, Lyngstad et al. 2008, Murray et al. 2010, Mardones et al. 2011, Rees et al. 2014, Stene et al. 2014a, Foreman et al. 2015b). Physical distance, along with ocean current speed and direction, ultimately determine connectivity among farms, and studies have also demonstrated that transport of pathogens by ocean currents can often better explain horizontal disease transmission between farms than geographic proximity alone (e.g. Euclidean and seaway distance) (Viljugrein et al. 2009, Stene et al. 2014b). 
Only a few models have explicitly evaluated the role of connectivity among farms in the transmission of piscirickettsiosis (Salama \& Murray 2012, Rees et al. 2014). In most of them, pathogens are typically assumed to have a fixed survival time outside the host (e.g. assuming an exponential decay rate) and passively drift with ocean currents. The effect of changes in oceanographic conditions, such as seawater temperature and salinity, on the survival of pathogens are rarely considered (Alaliyat et al. 2019a). The main objective of this study was to determine the influence of oceanographic conditions specifically hydrodynamic connectivity among farms, seawater temperature, and salinity - on the dispersal and prevalence of piscirickettsiosis at salmon farms in the Los Lagos region of southern Chile.

\section{MATERIALS AND METHODS}

Cultured salmon records (production and sanitary conditions) were combined with oceanographic modeling data (seawater temperature, salinity, and hydrodynamic connectivity among farms) to explore environmental drivers of piscirickettsiosis in the Los Lagos region of southern Chile (Fig. 1).

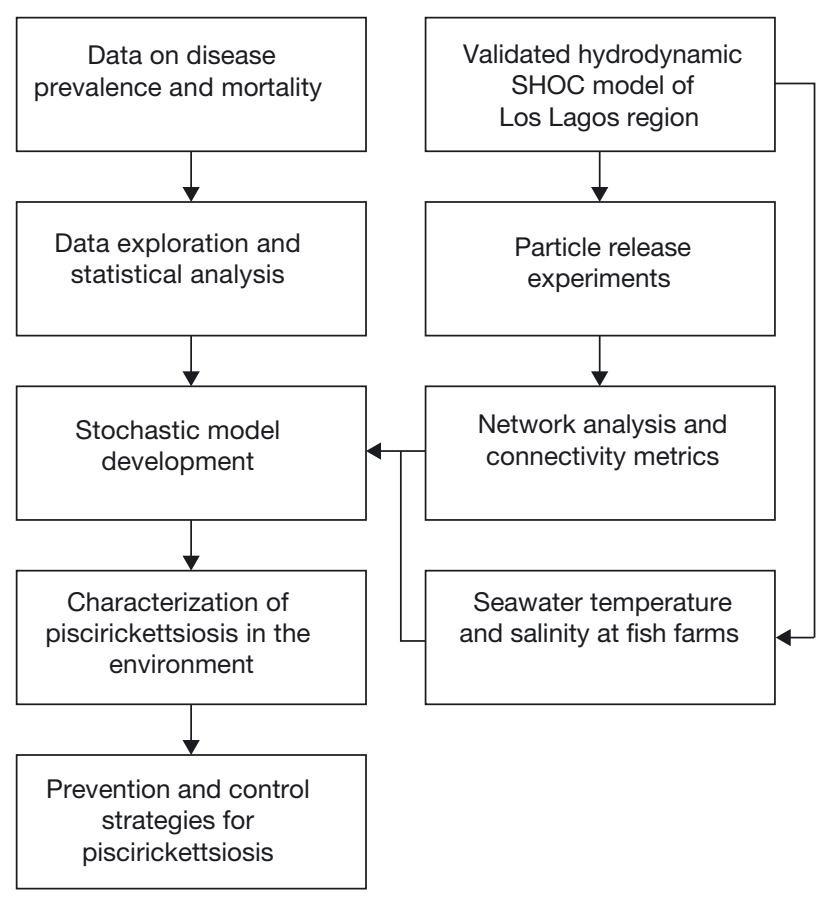

Fig. 1. Conceptual diagram of model development and application to explore environmental dependencies of piscirickettsiosis in open-cage marine salmon farms. SHOC: Sparse Hydrodynamic Ocean Code (Herzfeld 2006)

\subsection{Aquaculture data}

Salmon aquaculture data from January 2015 to December 2016 ( 103 wk in total) containing weekly records of fish population and mortality due to piscirickettsiosis were obtained from the National Fisheries Service of Chile (SERNAPESCA). The data were associated with 217 fish farm sites and 318 production cycles in the Los Lagos region. Mortality due to piscirickettsiosis was confirmed by certified laboratories through analysis of dead-fish tissue (brain, liver, or muscles) with PCR or indirect fluorescent antibody test (IFAT), following procedures defined by SERNAPESCA (2018d).

Pre-processing of the aquaculture data included removal of incomplete or incorrect records of fish weight (75 cases removed) and cage population (12 cases removed), using data validators defined by the Fundación para la Transferencia Tecnológica of Universidad de Chile (SERNAPESCA 2017a,b). Rare events of high mortality reported attributable to piscirickettsiosis were also removed to avoid skewed parameterization of the stochastic model due to low representativeness. These large mortality events were identified and removed from the data set using the $98^{\text {th }}$ percentile technique, which corresponded to cumulative observed mortalities in farms located in upstream waters above $\sim 600000$ deaths per farm in the previous 6 wk. As a result, 10650 mortality records attributed to piscirickettsiosis were included in the subsequent analysis. Cultured species included Salmo salar (Atlantic salmon), Oncorhynchus kisutch (coho or Pacific salmon), and O. mykiss (rainbow trout). Over $70 \%$ of the records were associated with Atlantic salmon.

\subsection{Oceanographic model data}

Predictions of seawater temperature, salinity, and water currents (speed and direction) were generated hourly by the calibrated Near-Real-Time Sparse Hydrodynamic Ocean Code (NRT SHOC, Herzfeld 2006) hydrodynamic model of the Los Lagos region. Details of the construction and validation of the hydrodynamic model from which connectivity matrices were derived are outlined in Herzfeld (2018) and Steven et al. (2019). Briefly, the hydrodynamic model was implemented on a fine-scale (600 m horizontal; $1-50 \mathrm{~m}$ vertical resolution) 3D grid of the Los Lagos inland sea and nested within a regional shelf and global ocean model (Oke et al. 2008) to allow for accurate inshore propagation of circulation and water properties. Atmospheric 


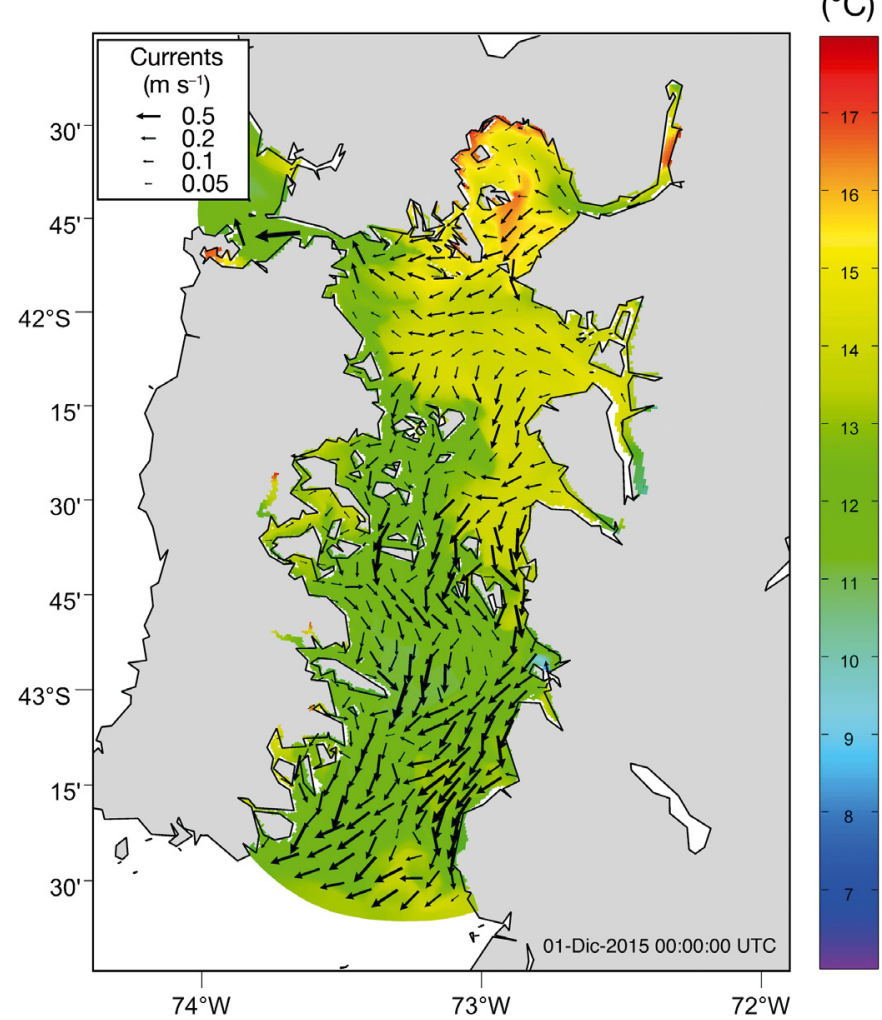

Fig. 2. Surface water temperature and surface current vector field for Los Lagos region, southern Chile, at midnight on 1 December 2015, generated by the hydrodynamic SHOC model (Herzfeld 2006)

fluxes were computed from the ACCESS-G global meteorological model, and daily river discharges for the 22 major river catchments in the region were simulated using the GR4J rainfall-runoff model (Perrin et al. 2003) with a snow component (Nepal et al. 2017). The output from the hydrodynamic model was combined in the connectivity tool CONNIE3 (CONNectivity InterfacE v3, https://connie.csiro.au/) with particle tracking techniques for assessing the connectivity between farms. A snapshot of the model predictions in the study area is shown in Fig. 2. At each farm location, the depth-weighted predictions of mean seawater temperature and salinity were calculated for the upper $20 \mathrm{~m}$ of the water column. Subsequently, weekly mean values were calculated to match the temporal scale of SERNAPESCA records.

The hydrodynamic connectivity among farms was predicted weekly during the study period (20152016) from particle release and tracking simulations representing the passive transport (drift due to ocean currents) of Piscirickettsia salmonis in seawater. To perform the simulations, a particle behavior model was developed to represent the survival of $P$. salmonis in seawater:

$$
\text { P. salmonis }(t)=P \text {. salmonis } e_{0} e^{-k t}
$$

where $k$ is the exponential mortality timescale $(2.5 \mathrm{~d})$ according to Almendras \& Fuentealba (1997), $P$. salmonis $s_{0}$ is the particle abundance of $P$. salmonis at $t_{0}$, and $t$ is the time after release in days. We assumed $P$. salmonis cells to be unattached to suspended solids, and settling velocity was assumed to be negligible.

There is a paucity of information on the incubation period of $P$. salmonis in salmonoids prior to the appearance of symptoms of disease. Three published reports quote incubation periods from 2-25 d (Smith et al. 1995, 2004, Almendras et al. 1997). Large variability in the reported incubation period of $P$. salmonis may be due to several factors, including virulence of the strain of bacteria, concentration of the pathogen in seawater, route of infection, and host immunity status. For this study, we hypothesized that farms reporting mortality attributed to $P$. salmonis in the SERNAPESCA records were carriers of the disease and actively shedding pathogens into seawater for at least $3 \mathrm{wk}(21 \mathrm{~d})$ prior to reported mortalities. We also hypothesized that at the beginning of the disease cycle on a farm the number of infected salmon would be low, and therefore $P$. salmonis shedding rates. With progression of the disease, bacteria shedding rates are expected to increase with the increase in the total number of infected fish. During the recovery phase, shedding rates decrease in response to treatment with drugs or natural recovery from disease. To estimate the transport and dispersal of $P$. salmonis, a conservative approach was used. The release of particles (i.e. representing the bacteria) from infected farms changes in equal increments of 100 particles $\mathrm{d}^{-1}$ in the range of 100 to 700 particles $\mathrm{d}^{-1}$ on Day 1 up to Day 7 , respectively, which represents the beginning of the infection cycle. Thereafter, a constant rate of 700 particles $d^{-1}$ were released from Days 8-15. After Day 15, the release of particles was decreased linearly to 100 particles $d^{-1}$ until Day 21, which represented the recovery phase of the disease. For simulations, particles were seeded at a depth of $3 \mathrm{~m}$ below the sea surface, which was considered the salmon swimming depth in the cages. This seeding rate adequately captures dispersal statistics, while maintaining relatively rapid computational rates. Following seeding, particles were tracked individually using a 4th-order Runge-Kutta ordinary differential equation solver, which uses linear interpolation to find the horizontal velocity at the required depth and time.

As the first step, simulations of particle release and tracking were replicated weekly for each farm in the study area to calculate potential pathogen connectiv- 
ity matrices among farms. The result of these simulations were weekly connectivity matrices in the form of $217 \times 217$ arrays, with rows corresponding to release sites (source farms) and columns corresponding to destination sites (sink farms). Each matrix element then represented the total number of $P$. salmonis particles arriving from each source or upstream farm to each sink or downstream farm. The potential connectivity between farms was defined as the dispersal potential of $P$. salmonis cells between farms, assuming all farms were shedding the bacteria into seawater, which was effectively the worst-case scenario. As explained below, potential connectivity matrices were corrected by the number of farms reporting piscirickettsiosis and the scale of a disease outbreak to provide a more realistic estimation of the risk of waterborne infection among farms.

\subsection{Risk metrics of waterborne infection}

Two exposure metrics of waterborne infection with $P$. salmonis were estimated from the combined analysis of potential connectivity matrices and mortality records due to piscirickettsiosis: the number of upstream shedding farms $\left(U I_{f}\right)$ and the cumulative exposure to waterborne infection from upstreaminfected farms $\left(C E_{m}\right)$.

$U I_{f}$ was predicted weekly through each farming cycle by cross-comparing the potential connectivity matrices (that identify upstream farms) with the mortality records attributed to piscirickettsiosis (that identify farms potentially shedding $P$. salmonis into seawater). Given that disease outbreak episodes can last for several weeks or more, observed mortalities due to piscirickettsiosis could be the result of cumulative exposure to multiple farms shedding the bacteria through variable periods. We assumed that infected farms located in upstream waters can influence disease dynamics in downstream farms for up to $6 \mathrm{wk}$. This time window of influence, or $w_{\max }^{\prime}$ accounts for (1) the time for transmission, which was limited to $30 \mathrm{~d}$, (2) the incubation period of the disease (up to $25 \mathrm{~d}$ ), and (3) the time between manifestation of first symptoms and mortality at downstream farms. Infected farms in upstream waters were counted each week they appeared in $w_{\max }^{\prime}$ (i.e. a maximum of 6 times for any farm). $U I_{f}$ was estimated from the following:

$$
\begin{gathered}
U I_{f}(f, w)=\sum_{w^{\prime}=0}^{w_{\text {max }}^{\prime}} \sum_{f^{\prime}=0}^{f_{\text {max }}^{\prime}} C M \\
C M=\left\{\begin{array}{l}
1, C_{f^{\prime}, f, w-w^{\prime}} \times M_{f^{\prime}, f, w-w^{\prime}}>0 \\
0, C_{f^{\prime}, f, w-w^{\prime}} \times M_{f^{\prime}, f, w-w^{\prime}}=0
\end{array}\right.
\end{gathered}
$$

where $w$ is the current week monitored, $f$ is the farm monitored (at a downstream position), $f^{\prime}$ represents the farms in the connectivity network, $w^{\prime}$ is the week monitored in the past, $f_{\text {max }}^{\prime}$ is the total number of farms in the connectivity network, $C_{f^{\prime}, f_{, W-W^{\prime}}}$ is hydrodynamic connectivity - specifically, the number of arriving particles to farm $f$ that were released from farm $f^{\prime}$ at week $W^{\prime}$, and $M_{f^{\prime}, W-w^{\prime}}$ is the mortality observed in the upstream farm $f^{\prime}$ at week $w^{\prime}$ (ind. $\mathrm{wk}^{-1}$ ) $C M$ is a discrete variable that takes the value of 0 when mortality and/or hydrodynamic connectivity equals 0 , or 1 in any other case.

$C E_{m}$ was computed as the cumulative product of the hydrodynamic connectivity calculated from the particle release experiments and the mortality attributed to piscirickettsiosis in upstream farms throughout $w_{\text {max }}^{\prime} . C E_{m}$ is considered a proxy for the pressure of infection of $P$. salmonis from upstream-infected farms, and was estimated from:

$$
C E_{m}(f, w)=\sum_{w^{\prime}=0}^{w_{\text {max }}^{\prime}} \sum_{f^{\prime}=0}^{f_{\text {max }}^{\prime}} C_{f^{\prime}, f, W-w^{\prime}} \times M_{f^{\prime}, f, W-w^{\prime}}
$$

$C E_{m}$ indirectly integrates other common metrics that are used to quantify infection pressure from nearby farms, such as the distance between farms (Euclidean and seaway distance) and the biomass concentration of cultivated fish $\left(\mathrm{t} \mathrm{km}^{-2}\right)$. In the computed connectivity, the released particles were counted as many times as they entered the cell grids where downstream farms were located. The latter condition allows a more realistic estimation of risk of waterborne transmission; nonetheless, the drawback of this simulation setup is that it did not allow us to normalize the connectivity values, specifically, of the number of arriving particles by the total number of released particles, which would be desirable to cancel the 'particles' unit of $C E_{m}$. As a result, the units of $C E_{m}$ are number of dead fish $\times$ arriving hydrodynamic particles.

\subsection{Data exploration}

An exploratory analysis based on the calculation of prevalence ratios (or attributable risk) was carried out to explore environmental conditions (exposures) as risk factors of piscirickettsiosis on the fish farms in the Los Lagos region. The prevalence ratio expresses the proportion of farms reporting mortality due to piscirickettsiosis to the total number of farms exposed to a risk factor, in this case, temperature, salinity, and hydrodynamic connectivity among farms. The statistical significance of the observed differ- 
ences in prevalence ratios was tested using a chisquared test that compares the observed to expected values assuming no relationship between exposure and disease outcome. Only results with a probability of a Type I error (rejecting a true null hypothesis) lower than $5 \%$ are reported in the results. Prevalence ratios were computed using $\mathrm{R}$ (version 3.6.2, R Studio version 1.2.5033); specifically, the function 'epi.2by2' of the 'epiR' package (Stevenson et al. 2013).

Threshold values $\left(C E_{m, t h r}, T_{t h r}, S_{t h r}\right)$ were defined at regular intervals within the predicted range of each risk factor to discriminate (and to bin) exposed from unexposed cases (e.g. mortality records above and below $15^{\circ} \mathrm{C}$ ) and estimated prevalence ratios. This approach allowed us to determine the existence of threshold values of $C E_{m}$, seawater temperature and salinity at which piscirickettsiosis prevalence was significantly different (higher or lower).

\subsection{Stochastic model}

A stochastic, state-based, time-dependent epidemiological model was developed to understand the dynamics of piscirickettsiosis over a fish farm production cycle. The model was built by combining mortality records attributed to piscirickettsiosis and the connectivity metrics defined above. The model assumes that each week, the fish at a farming site could be in one of the following 3 disease states: disease-free $(F)$, infected $(I)$, or recovered $(R)$. $F$ indicates that no fish mortality due to piscirickettsiosis has been observed throughout the farming cycle, whereas $R$ indicates that although fish mortality due to piscirickettsiosis has not been reported in the present week, such deaths had occurred earlier in the production cycle. In total, there were 6 possible transitions between disease states: $F \rightarrow I, I \rightarrow R, R \rightarrow I, F \rightarrow F$, $I \rightarrow I$, and $R \rightarrow R$. A schematic of the model is shown in Fig. 3. $F$ was transient; all farms started in $F$ and could move to a state of $I$ and $R . I$ and $R$ are the recur-

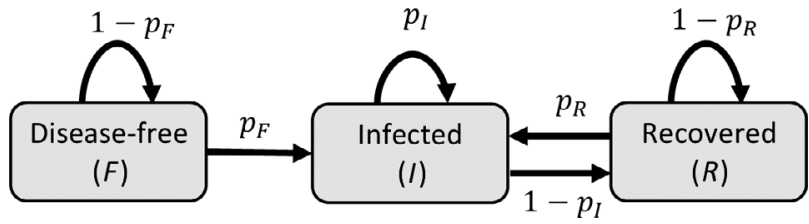

Fig. 3. Stochastic representation of piscirickettsiosis dynamics at salmon farm sites. The model includes 3 disease states (boxes) and 6 possible weekly state transitions (arrows). $p_{F}$ $p_{I}$ and $p_{R}$ represent the probability of being infected $(I)$ at week $w$ having been in a disease-free $(F), I$, or recovered $(R)$ state at week $w-1$ rent states, as it is not possible to return to $F$.

The likelihood of a farm reporting mortality due to piscirickettsiosis was related to the disease status of the farm in the previous week along with the following 4 covariates: (1) the number of farms in upstream waters that reported mortality and were therefore assumed to be shedding $P$. salmonis into seawater (i.e. $\left.U I_{f}\right)$; (2) the mortality due to piscirickettsiosis in the upstream farms corrected by the hydrodynamic connectivity (i.e. $C E_{m}$ ); (3) the week of the year that the farms were stocked with salmon smolts; (4) the depth-weighted predictions of mean seawater temperature and (5) salinity. The model parameters were estimated to maximize the likelihood (or probability) of the model generating the observed data. This was achieved using a Monte Carlo Markov chain approach, which considered all plausible stochastic pathways between time observations. At this point, the model only focuses on the role of environmental conditions and precludes the influence of other relevant covariates such as the fallow period, stocking density, stocking weight, stocking date, fish species, vaccination status, antibiotic treatments, and the influence of other viral and parasite co-infections.

\section{RESULTS}

\subsection{Production statistics and sanitary conditions at fish farm sites}

Descriptive statistics of the 318 salmon production cycles are presented in Table 1 . The average $( \pm \mathrm{SD})$ length of the fish farm cycles was $48.2 \pm 25.3 \mathrm{wk}$ (max.: $89 \mathrm{wk}$ ). The variability in farming cycle length was mostly due to differences in the intrinsic growth rates among salmonid species (e.g. Oncorhynchus kisutch have the shortest production cycle), temperature dependencies, and harvesting due to disease outbreaks. Farm stocking and harvesting occurred throughout the year, although most harvesting was concentrated between September and March. The average fish population was $817059 \pm 319037$ ind. farm $^{-1}$.

The average weekly fish mortality attributed to piscirickettsiosis was highly variable, reaching a maximum of $6.2 \% \mathrm{wk}^{-1}$ ( 52000 fish week ${ }^{-1}$ farm $\left.^{-1}\right)$. This estimate does not account for massive outbreaks filtered from the data set, which were as high as $34.2 \%$ of the farm population. The cumulated mortality due to piscirickettsiosis in upstream farms averaged 8143.7 fish within the monitored $w_{\max }^{\prime}$ (max. 209641 fish). $C E_{m}$ associated with farms reporting mortality 
Table 1. Summary statistics of salmon fish farm cycles considered within the study $(\mathrm{n}=318)$ and observed variability in oceanographic conditions. $w_{\max }^{\prime}$ : window of influence

\begin{tabular}{|c|c|c|}
\hline Statistics & Mean $\pm \mathrm{SD}$ & Range \\
\hline Length of fish farm cycles (wk) & $48.3 \pm 25.3$ & $16-89$ \\
\hline Fish biomass per farm at the end of the farming cycle $\left(\mathrm{t} \mathrm{farm}^{-1}\right)$ & $2341.72 \pm 1383.9$ & $0-8753.2$ \\
\hline Fish population per farm (fish farm ${ }^{-1}$ ) & $817059 \pm 319037.4$ & $0-2599377$ \\
\hline Weekly mortality attributed to piscirickettsiosis (fish wk ${ }^{-1}$ ) & $304.7 \pm 1264.7$ & $0-52409$ \\
\hline Weekly mortality rate attributed to piscirickettsiosis ( $\%$ fish $w^{-1}$ ) & $0.04 \pm 4.26$ & $0-6.17$ \\
\hline $\begin{array}{l}\text { Weekly no. of upstream farms (infected, non-infected, and non-operating) } \\
\text { from connectivity matrices }\end{array}$ & $15.3 \pm 22.5$ & $0-152$ \\
\hline Weekly no. of infected farms in upstream waters from connectivity matrices & $2.45 \pm 4.26$ & $0-36$ \\
\hline No. of upstream farms (infected, non-infected, and non-operating) in $w_{\max }^{\prime}{ }^{a}$ & $95.4 \pm 124.7$ & $0-743$ \\
\hline No. of infected farms in upstream waters in $w_{\max }^{\prime}\left(U I_{f}\right)$ & $15.6 \pm 23.2$ & $0-190$ \\
\hline Mortality attributed to piscirickettsiosis in upstream farms in $w_{\max }^{\prime}$ & $8143.7 \pm 19248.2$ & 0-209641 \\
\hline Cumulative exposure to waterborne infection from upstream infected farms $\left(C E_{m}\right)$ & $4.1 \times 10^{4} \pm 9.4 \times 10^{4}$ & $0-6.3 \times 10^{5}$ \\
\hline Temperature $(T)$ predicted at fish farms sites throughout the study period $\left({ }^{\circ} \mathrm{C}\right)$ & $12.0 \pm 1.5$ & $7.2-17.1$ \\
\hline Salinity $(S)$ predicted at fish farms sites throughout the study period (PSU) & $31.6 \pm 1.8$ & $18.1-33.5$ \\
\hline
\end{tabular}

due to piscirickettsiosis in $W_{\text {max }}^{\prime}$ averaged $4.1 \times 10^{4} \pm$ $9.4 \times 10^{4}$ dead fish $\times$ arriving hydrodynamic particles $\left(\max .: 6.3 \times 10^{5}\right)$.

According to the predictions of potential hydrodynamic connectivity, farms were connected weekly to an average of $15.3 \pm 22.5$ farms (including infected, non-infected, and non-operating farms). The connectivity decreased to $2.45 \pm 4.26$ farms (max.: 36) when considering only those farms located in upstream waters reporting mortality attributed to piscirickettsiosis. When considering $w_{\text {max }}^{\prime}$ (i.e. 6 wk in the past), the number of upstream farms reporting mortality attributed to piscirickettsiosis (i.e. $U I_{f}$ ) was $15.6 \pm 23.2$ farms (median: 6 farms) and reached up to 190 farms in the most extreme cases considered in the analysis. It is important to recall that in the case of $U I_{f}$, each farm was counted every week it was both reporting mortality due to piscirickettsiosis and connected hydrodynamically with a downstream farm (i.e. up to 6 times farm $^{-1}$ ).

\subsection{Oceanographic conditions at fish farm sites}

Summary statistics of the observed variability in predicted oceanographic conditions (temperature and salinity) at the fish farm sites are summarized in Table 1. Over the study period (2015 to early 2017), the depth-weighted predictions of mean surface salinity and temperature within the upper $20 \mathrm{~m}$ of the water column at fish farm sites were $12.0 \pm 1.5^{\circ} \mathrm{C}$ and $31.6 \pm 1.8 \mathrm{PSU}$, respectively. Seawater temperatures ranged from $7.2-17.1^{\circ} \mathrm{C}$ and decreased with increas- ing latitude (Fig. 4A). The highest predicted seawater temperatures were in the areas of high water residence time (e.g. Reloncaví Sound, Comau Fjord, and Riñihué Fjord), whereas the lowest values were at farms along the western side of the Gulf of Corcovado (Fig. 4C).

In contrast, salinity increased towards the southwest, with the lowest values ( 18 PSU) at farms on the continental side of the inner sea of Chiloe where freshwater inputs are mostly concentrated (e.g. Reloncaví Fjord, Comau Fjord, and Riñihué Fjord, Chaitén), and the highest values at farms along the east coast of Chiloe Island. This pattern agrees with field observations reported in Steven et al. (2019) and references therein.

\subsection{Observed fish mortality attributed to piscirickettsiosis}

The risk of waterborne transmission of piscirickettsiosis among farms was estimated by a combined analysis of potential connectivity matrices and recorded mortality data for the years 2015 and 2016. The observed prevalence of piscirickettsiosis organized by week of the farming cycle is shown in Fig. 5. As evident from Fig. 5A, the observed prevalence of piscirickettsiosis increased progressively over the farming cycles, reaching almost $100 \%$ by Week $\sim 60$. Due to the low number of cases, no significant differences were found in observed prevalence after Week 60. Disease prevalence increased through spring (Weeks 37-50) and peaked in early summer (Fig. 5B). 

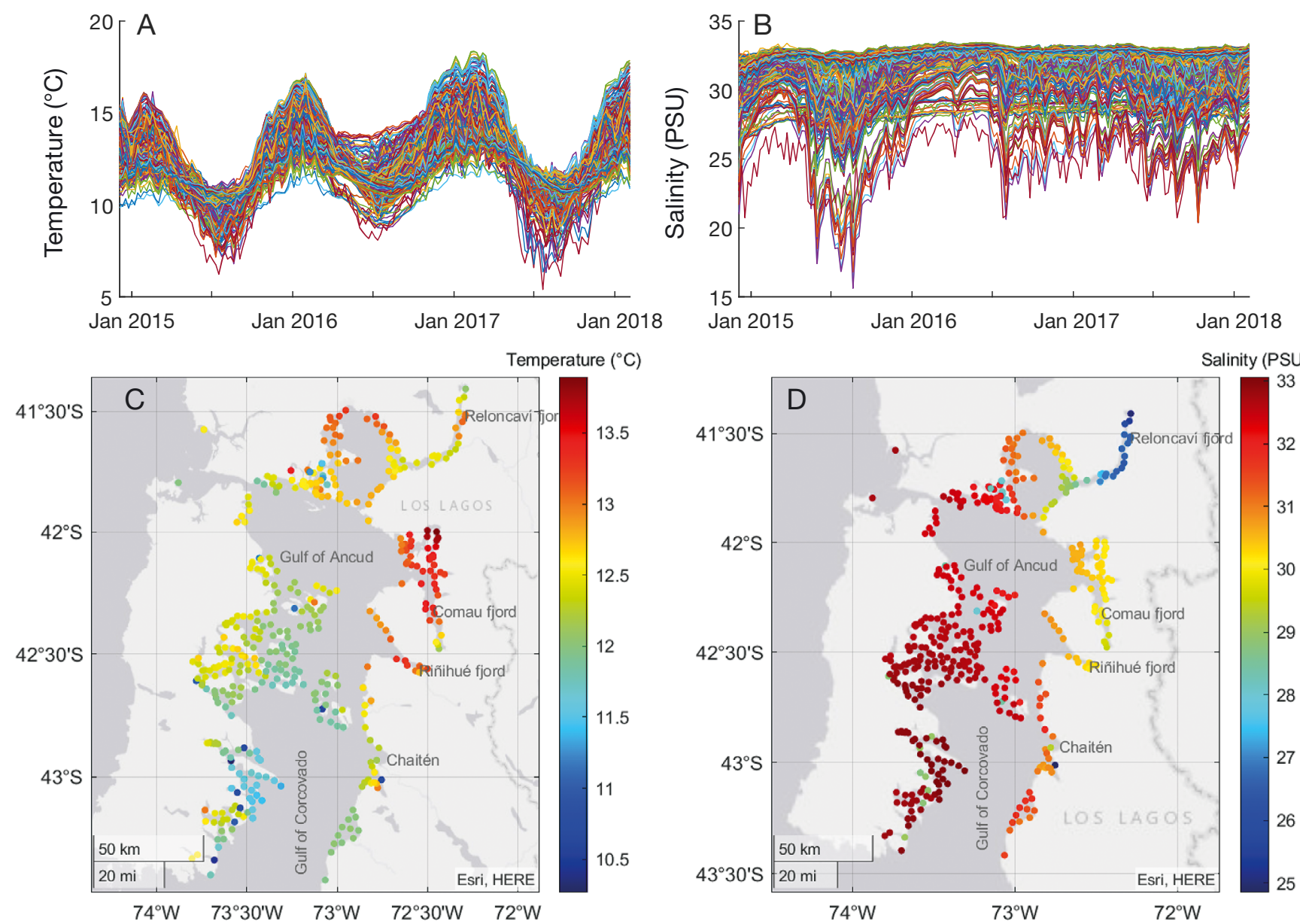

Fig. 4. Time series of depth-integrated (A) temperature and (B) salinity records for the upper $20 \mathrm{~m}$ at 498 fish farm sites located in the Los Lagos region, and model predictions of the mean (C) temperature and (D) salinity at 478 fish farm locations in the Los Lagos region for the period 2015-2017
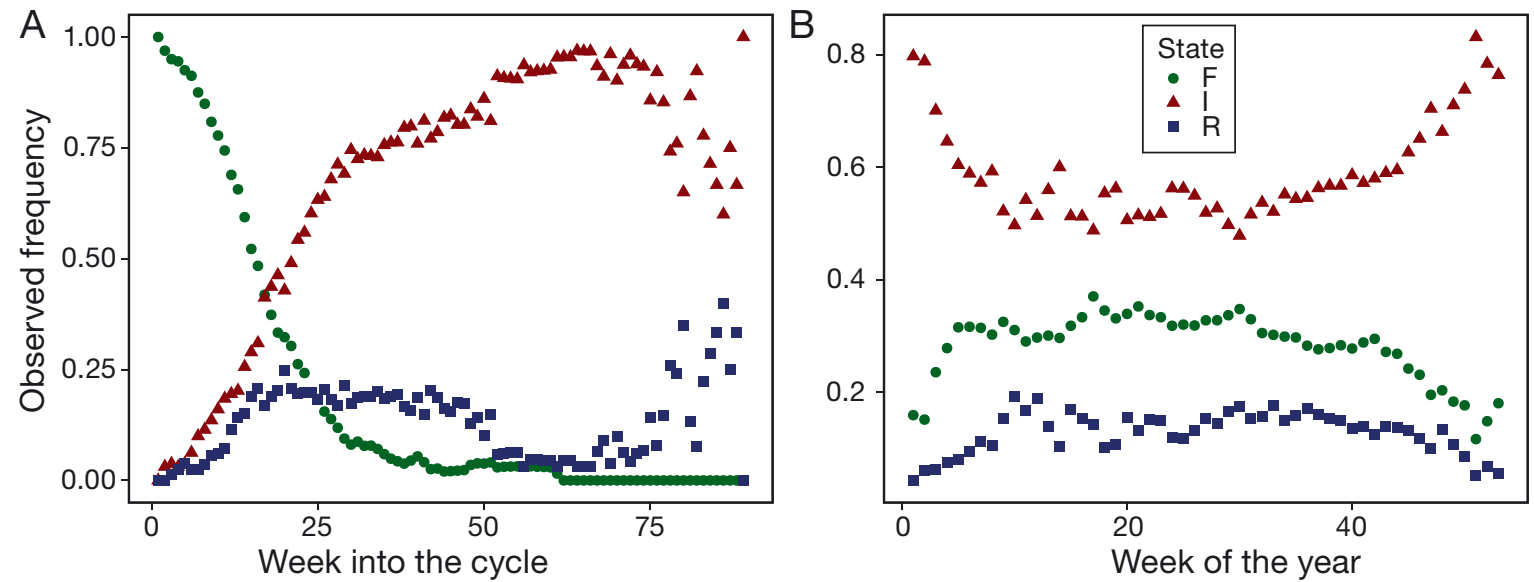

Fig. 5. Observed piscirickettsiosis disease dynamics at salmon farms in the Los Lagos region, by (A) week of the production cycle and (B) week of the year. Disease state: $F$ : disease-free; $I$ : infected; $R$ : recovered

\subsection{Role of upstream infection, water temperature, and salinity}

The observed prevalence of piscirickettsiosis over the 318 farming cycles is presented in Fig. 6. Mortal- ity records were grouped using threshold values as described in Section 2.4 and only included production cycles that showed a significant difference $(\mathrm{p}<$ 0.05 ) in observed prevalence ratios between exposed and unexposed groups. 

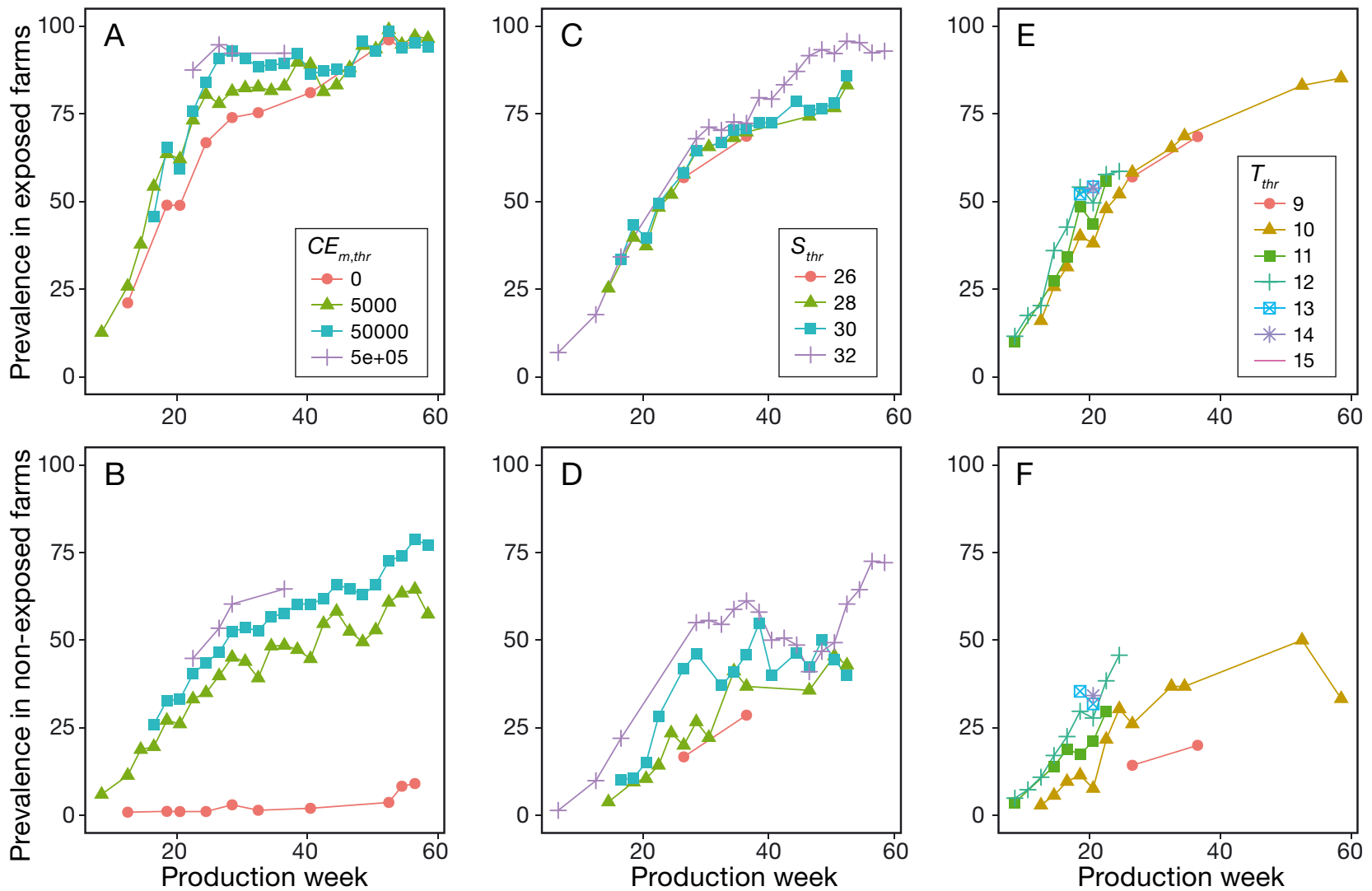

Fig. 6. Observed piscirickettsiosis prevalence at the salmon farms as a function of multiple thresholds in the cumulative exposure to upstream mortality corrected by the strength of $(\mathrm{A}, \mathrm{B})$ farm-to-farm hydrodynamic connectivity $\left(C E_{m}\right),(C, D)$ salinity, and $(E, F)$ temperature. $C E_{m, t h r}$ : threshold cumulative exposure to waterborne infection from upstream-infected farms (no. of dead fish $\times$ arriving hydrodynamic particles); $S_{t h r}$ salinity threshold (PSU); $T_{t h r}$ : temperature threshold $\left({ }^{\circ} \mathrm{C}\right)$

The observed piscirickettsiosis prevalence increased over the farming cycle independently of the oceanographic conditions (salinity, temperature, and connectivity). Nonetheless, as observed in Fig. 6A, C,E, a relatively faster increase in the prevalence of piscirickettsiosis was observed for $C E_{m}$ compared to temperature or salinity. The prevalence of piscirickettsiosis became significantly higher after Week 10 in those farming cycles exposed to waterborne infection (i.e. with $C E_{m}>C E_{m, t h r}$, independently of the $C E_{m, t h r}$ value selected to group the data (exposed vs. unexposed cases).

The observed piscirickettsiosis prevalence in the farms not exposed to waterborne transmission $\left(C E_{m}=\right.$ 0 ) was low, reaching only $\sim 10 \%$ by the end of the farming cycle (Weeks 54-56) (Fig. 6B). These records were associated with isolated inshore farms with little or no exposure to upstream farms. This observation underscores the important role of hydrodynamic connectivity in the transmission of piscirickettsiosis among farms in the Los Lagos region. As evident from Fig. 5B, in the unexposed farms $\left(C E_{m, t h r}=0\right)$, low prevalence of disease could potentially be due to localized sources of infection at the farms.

The likelihood of observed mortality being driven by waterborne pathogens increased when higher $C E_{m, t h r}$ values were used, as only the cases associated with the highest $C E_{m}$ values remain in the exposed group. As evident in Fig. 6A, no meaningful difference in disease prevalence was observed when data were grouped using $C E_{m, t h r}$ values $>5000$. For the unexposed farms $\left(C E_{m}<C E_{m, t h r}\right)$ the prevalence of piscirickettsiosis increased as increasingly higher $C E_{m, t h r}$ values were used to discriminated exposed and unexposed farms. These observations suggest that the exposure level to waterborne infection required to trigger infection and mortality at downstream farms is relatively low.

As observed in Fig. 5C,D, the prevalence of piscirickettsiosis increased with predicted salinity in the study area (26-32 PSU). In farms where salinity was greater than $32 \mathrm{PSU}$, the disease prevalence was over $90 \%$ by the end of the farming cycle (Week $\sim 58$ ), whereas below this salinity the maximum pre- 
valence of the disease was $75 \%$. At Week 37 of the production cycle, the observed prevalence in farms with predicted salinity above 26 PSU was $~ 74 \%$ compared to a maximum of $29 \%$ at salinity below 26 PSU.

Piscirickettsiosis prevalence also increased with seawater temperature (Fig. 5E,F). At Week 36 of the farming cycle, the observed prevalence of piscirickettsiosis at seawater temperature above $9^{\circ} \mathrm{C}$ was as high as $70 \%$ (Fig. 6E), while below this temperature it was as high as $20 \%$ (Fig. 6F). At Week 41, the prevalence of piscirickettsiosis in farms exposed to seawater temperatures above $15^{\circ} \mathrm{C}$ was up to $~ 88 \%$ and decreased to $\sim 65 \%$ below this threshold.

\subsection{Stochastic model}

A stochastic model was built to predict the role of risk factors on the incidence of piscirickettsiosis $\left(U I_{f t}\right.$ $C E_{m}$, temperature, salinity and stocking week of the year). Results show that disease dynamics simulated



Cumulative exposure to upstream infected farms (dead fish $\times$ arriving particles) $=10000$ Salinity $(\mathrm{PSU})=25$

Temperature $\left({ }^{\circ} \mathrm{C}\right)=10$

Stocking week of the year $=30$

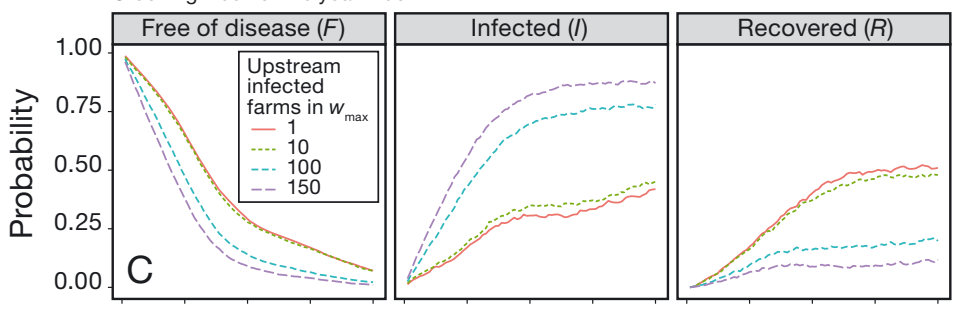

Number of upstream infected farms $=20$

Cumulative exposure to upstream infected farms (dead fish $\times$ arriving particles) $=10000$ Salinity (PSU) $=25$

Temperature $\left({ }^{\circ} \mathrm{C}\right)=10$

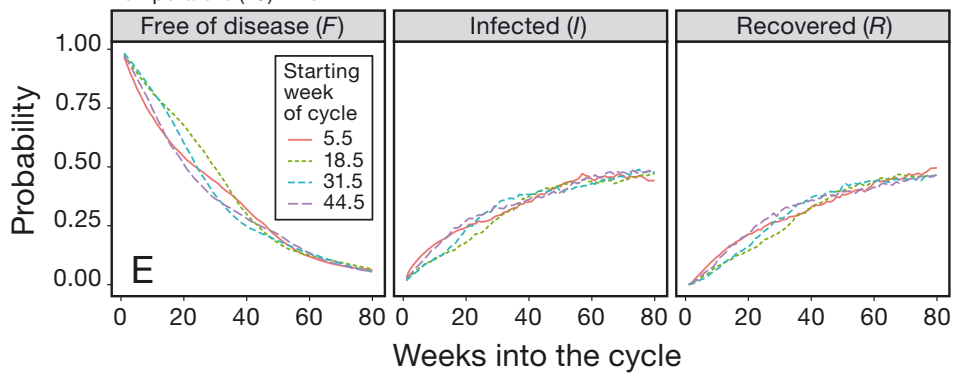

by the model fit with the observed prevalence patterns shown in Fig. 5. The increase in the probability of a farm being infected over the farming cycle stabilizes around Week 40, as observed in Fig. 5. The model also replicated the influence of model covariates on piscirickettsiosis disease dynamics. The covariates that influence the probability of piscirickettsiosis infections, in descending order of importance, were (1) $U I_{f}$ in $W_{\max }^{\prime}$ (depends on distance among farms, speed and current direction), (2) $C E_{m}$, followed by (3) salinity, and finally (4) temperature.

The influence of risk factors (covariates) on piscirickettsiosis dynamics were evaluated one at a time. A slight increase in the probability of piscirickettsiosis infection was predicted with an increase in the seawater temperature at the fish farm sites (Fig. 7A).

The model correctly predicted an increase in the prevalence of piscirickettsiosis with an increase in salinity from 20-32 PSU (Fig. 7B). In general, the probability of disease increased more rapidly at

Number of upstream infected farms $=20$

Cumulative exposure to upstream infected farms (dead fish $\times$ arriving particles) $=10000$ Temperature $\left({ }^{\circ} \mathrm{C}\right)=10$

Stocking week of the year $=30$

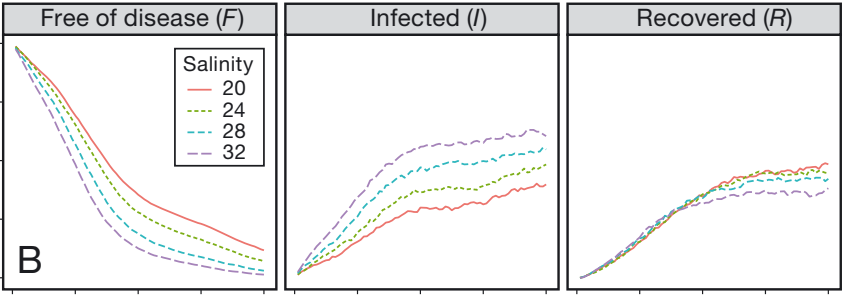

Number of upstream infected farms $=20$

Salinity (PSU) $=25$

Temperature $\left({ }^{\circ} \mathrm{C}\right)=10$

Stocking week of the year $=30$

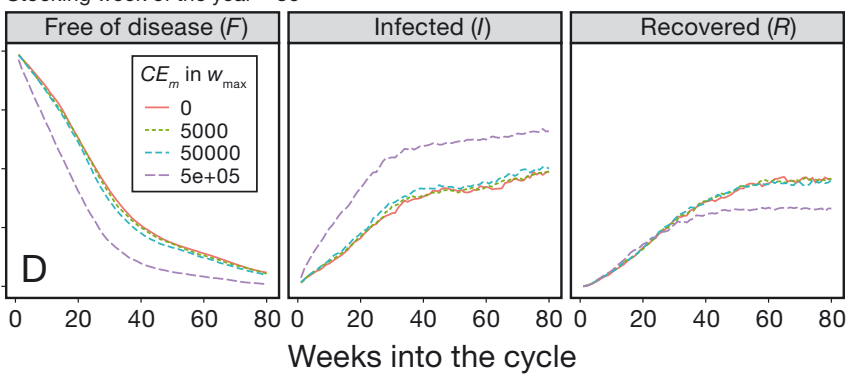

Fig. 7. Predicted piscirickettsiosis disease dynamics at marine salmon farms, predicted as a function of the week of the production cycle and (A) surface temperature, (B) surface salinity, (C) the number of upstream infected sites in the $6 \mathrm{wk}$ window of influence $\left(w_{\max }^{\prime}\right)$ (farms were counted each week they were predicted in upstream waters in $w_{\max }^{\prime}$ ), (D) the mortality due to piscirickettsiosis in upstream farms corrected by the strength of farm-to-farm hydrodynamic connections $\left(C E_{m}\right)$, and (E) the week of the year at which the farm was stocked with salmon smolts, specifically mid-fall (Week 5.5 of the year), mid-winter (Week 18.6), mid-spring (Week 31.5), and midsummer (Week 44.5) 
higher salinity, reaching $>60 \%$ toward the end of the cycle (Week 58) at 32 PSU. At Week 40 of the production cycle, the predicted probability of disease was $\sim 56 \%$ at 32 PSU compared to $\sim 26 \%$ at 20 PSU. The overall influence of salinity on the prevalence of disease was higher than temperature, which agrees with observed prevalence ratios shown in Fig. 6E,F. However, low salinity values ( $<25$ PSU) were only observed occasionally in areas heavily influenced by freshwater inputs (Fig. 3); the minimum average salinity predicted at the fish farm sites was around 25 PSU.

In this study, 2 metrics related to hydrodynamic connectivity $\left(U I_{f}\right.$ and $C E_{m}$ ) were incorporated into the stochastic model. These are not independent factors, as $C E_{m}$ depends on the number of upstream farms reporting mortality attributed to piscirickettsiosis as well as the strength of hydrodynamic connectivity between farms, which hinders the establishment of the individual role of each risk factor. As observed in Fig. $7 \mathrm{C}$, the model fits suggested that piscirickettsiosis was more likely to be prevalent when farms were exposed to an increasing number of infected farms in upstream waters. The transition from states of $F$ to $I$ (probability greater than $50 \%$ ) was predicted much earlier ( Week 15-20) in farms exposed to more than 100 upstream infected farms in $W_{\max }^{\prime}$ compared to farms exposed to 10 or less upstream infected farms in $W_{\max }^{\prime}$, where the probability of recovery was much higher.
The stochastic model fits also suggested an increase in piscirickettsiosis incidence with an increase in fish mortality in the upstream farms as expressed by $C E_{m}$ (Fig. $7 \mathrm{D}$ ). However, the impact of $C E_{m}$ is predicted to be meaningful only at values above $5 \times 10^{5}$, which is rather considered an artefact of analyzing one factor at a time and assuming a constant value for the rest of the covariates, particularly the number of upstream infected farms (in this case fixed at 20), as explained above. Finally, the stochastic simulations covering all 4 seasons indicated that the week of the year for stocking salmon smolt had little influence on the predicted incidence of piscirickettsiosis (Fig. 7E).

\subsection{Application of the stochastic model to predict risk}

To evaluate the performance of the developed stochastic model, we applied it to the reported disease prevalence data set (318 farming cycles) for the Los Lagos region (Fig. 8). Two scenarios were considered: (1) exposure to upstream farms reporting fish mortality due to piscirickettsiosis and (2) farms which were not exposed to upstream infected farms as predicted from our hydrodynamic connectivity model (represented by $C E_{m}$ ). The $C E_{m}$ value for the exposed scenario was set equal to $1 \times 10^{4}$ (maximum feasible predicted $C E_{m}=2 \times 10^{6}$ in the study period
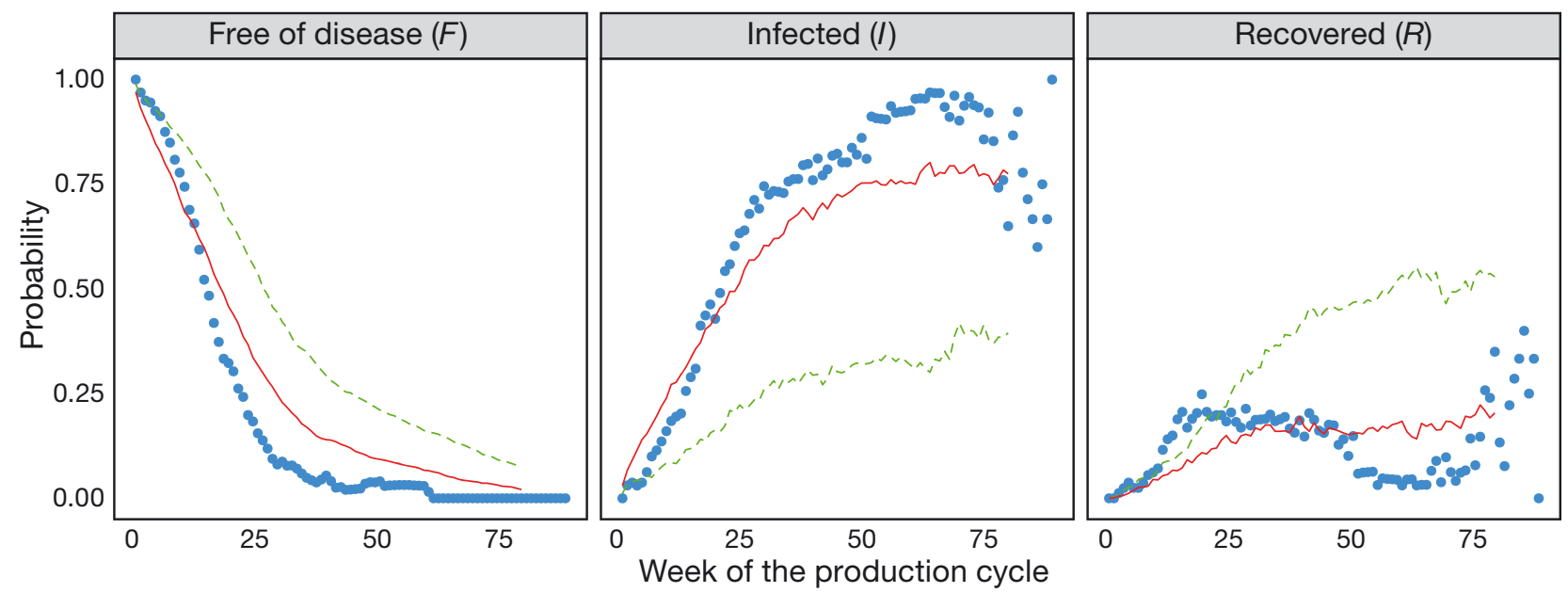

\footnotetext{
- Observed frequency

Parameters of the modeled scenario:

Salinity $(\mathrm{PSU})=25$

Temperature $\left({ }^{\circ} \mathrm{C}\right)=10$

Stocking week of the year $=30$
}

- - No exposure to upstream infected farms with $\operatorname{SRS}\left(C E_{m}=0\right)$

- Modeled scenario

Number of upstream infected farms $w_{\text {max }}^{\prime}=100$

Cumulative exposure to upstream infected farms (dead fish $\times$ arriving particles) $=10000$

Fig. 8. Piscirickettsiosis dynamics as a function of the week of the salmon farming cycle, showing predicted (lines) and observed (dots) exposure scenarios. In both cases, temperature, salinity, and stocking week of the farm were assumed constant 
and area), while temperature and salinity were set to $10^{\circ} \mathrm{C}$ and 31.5 PSU. The stocking date of farms was set at Week 30 of the year, and the number of upstream infected farms was assumed constant for the entire farming cycle and set at 100. It is important to mention that the latter value can be achieved by multiple combinations of upstream infected farms (e.g. 16 farms shedding $P$. salmonis into upstream waters in the $6 \mathrm{wk} W_{\max }^{\prime}$ ).

The observed disease prevalence frequency was very similar to the probability curve of being infected over the production cycle (blue dotted curve vs. solid red line in Fig. 8). The predicted probability of disease-free cycles for farms exposed to upstream infection rapidly declined from the stocking time to Week 25 of production. The probability of the farms that were exposed to upstream infected farms being infected closely matched with the recorded disease prevalence. The rate of probability change from the onset of the farming cycle was slightly higher than the observed prevalence. The observed and predicted prevalence plateaued at about the same week (Week 40) at a value close to $90 \%$ (Fig. 8B).

\section{DISCUSSION}

Spatial management is increasingly considered as an important tool for protecting fish health and reducing disease outbreaks (Salama \& Murray 2011, Murray \& Gubbins 2016, Alaliyat et al. 2019b). Hydrodynamic models combined with particle tracking models can provide information on the risk of being exposed to pathogens from neighboring farms. In this study, we combined weekly mortality records attributed to piscirickettsiosis with hydrodynamic model data to establish relationships beyond areas of coordinated management and across the entire connectivity network in the Los Lagos region. We built on previous knowledge by analyzing how the number of infected farms in upstream waters, the strength of hydrodynamic connectivity, and the scale of disease outbreaks (inferred from fish mortality at individual farms), along with seawater temperature and salinity, explain the prevalence of piscirickettsiosis. The purpose of building this model was to identify piscirickettsiosis risks in space and time.

As evident from the results of this study, during the period of analysis (2015-2016), <2\% of the farming cycles were found to be disease-free until harvesting. Furthermore, during 2015 and 2016, the mortality in extreme disease outbreak events was observed to be as high as $34.2 \%$ of the population. This suggests that none of the current disease prevention and control strategies are completely effective.

This study suggests that disease dynamics in upstream farms (in terms of the number of infected sites and mortality per farm), hydrodynamic connectivity, salinity, and water temperature have complex interactions that ultimately determine the risk of infection. The stochastic model we developed allows for further exploration of these interactions. Despite complex interactions between on-farm disease dynamics and the physical environment (ocean currents, temperature, and salinity), our model successfully demonstrated the relative importance of factors that influence the probability of infection. In order of relevance, the covariates that have the most influence on the probability of infection are (1) the number of upstream infected farms, (2) the intensity of singlefarm disease outbreaks (represented by fish mortality), (3) salinity, and (4) temperature. Further understanding of the interactions between these risk factors may help to target and determine more effective disease management and control strategies. The results are consistent with previous studies where the risk of transmission of piscirickettsiosis has been reported to be influenced by water temperature, salinity, and proximity to infected farms (Rees et al. 2014, Price et al. 2017).

\subsection{Hydrodynamic connectivity is a major driver of disease}

Passive dispersal of salmon pathogens such as hematopoietic necrosis virus, infectious salmon anemia, and sea lice from farm to farm via ocean currents has been well documented (Gustafson et al. 2007, Jansen et al. 2012, Kristoffersen et al. 2013, Salama \& Murray 2013, Foreman et al. 2015b, Murray \& Gubbins 2016). In this study, the prevalence of piscirickettsiosis at farms exposed to upstream infection was observed to be $60 \%$ at Week $~ 15$ and increased to $>90 \%$ after Week $\sim 25$ of the production cycle. In comparison, in unexposed farms, the observed prevalence of piscirickettsiosis was $60 \%$ at Week 30 and reached a maximum of $78 \%$ towards the end of the production cycle at Week 60 (Fig. 6A). This observation suggests that hydrodynamic connectivity among farms is the major driver of the disease, and that farms in the Los Lagos region are significantly inter-connected through ocean currents.

A second conclusion that arises from statistical analysis is that the level of exposure in terms of upstream infected farms required to trigger piscirickettsiosis 
infection and mortality at downstream farms appears to be relatively low compared to the maximum range of exposure predicted in this study. A similar conclusion is apparent from the stochastic modeling results applied to historic piscirickettsiosis disease outbreak data. Nonetheless, further research is necessary to characterize the precise level of exposure required to trigger infections in disease-free farms and potential carriage of bacteria from one production cycle to the next.

It is noteworthy that the piscirickettsiosis incidence on the farms that did not show strong hydrodynamic connectivity with our model also increased, over time, with an increase in reported mortality in upstream farms (Fig. 6B). This is most likely due to an underestimation of the connectivity within this study, as very conservative bacteria shedding rates and survival time of bacteria in the environment were used. Also, high Piscirickettsia salmonis load in the water is expected to result in a larger impact area or greater connectivity than estimated. Furthermore, the probability of piscirickettsiosis depends on the exposure dose of P. salmonis (Garcés et al. 1991), which is expected to increase with an increase in the rate of disease prevalence in the upstream farms.

The disease prevalence in the farms with very low or no hydrodynamic connectivity to upstream farms was low, increasing only to $\sim 10 \%$ by the end of the farming cycle (Weeks 54-56) (Fig. 6B). We explored the records of these farms, which were a small group of farms located inshore in isolated areas with little to no hydrodynamic connectivity with surrounding farms. The fact that the observed prevalence of piscirickettsiosis in farms not exposed to upstream infection (i.e. $C E_{m}=0$ ) is considerably low suggests that the major route of disease transmission is the passive movement of waterborne $P$. salmonis via ocean currents. The source of infection in the isolated farms is most likely to be localized, such as a lapse in sanitation conditions or by carriers of the disease (e.g. wild fish have been reported to be the carrier of $P$. salmonis; Contreras-Lynch et al. 2015). Further research is required to establish the causes of disease outbreaks in isolated farms, as this information is vital for understanding the mechanism of transmission and control of P. salmonis.

\subsection{Role of temperature and salinity}

The results of this study suggest that temperature and salinity are positively correlated with fish mortality due to piscirickettsiosis. At Week 36 of the farming cycle, the observed prevalence of piscirickettsiosis at below $9^{\circ} \mathrm{C}$ water temperature was approximately $20 \%$, whereas at temperatures above $9^{\circ} \mathrm{C}$, disease prevalence increased by up to $70 \%$ (Fig. 6C,D). At Week 41, the prevalence of piscirickettsiosis in farms exposed to temperatures above $15^{\circ} \mathrm{C}$ was up to $\sim 88 \%$ and decreased to $\sim 65 \%$ below this threshold. A positive correlation between seawater temperature and piscirickettsiosis has been reported previously (Rees et al. 2014).

The results of this study also suggest a higher prevalence of piscirickettsiosis $(74 \%)$ at salinity $>26 \mathrm{PSU}$ compared to a much lower prevalence $(<29 \%)$ at salinity <26 PSU. Despite the higher mortality observed with an increase in water temperature and salinity, the mechanisms involved remain unclear, and further work is required to determine the role of temperature and salinity on disease dynamics. For instance, this association may be due to the increased metabolic activity of both host and pathogens at higher water temperatures (Schulte 2015). It is also possible that other indirect factors which induce stress in farmed fish, such as high salinity, low oxygen availability (controlled by ocean current speed and solubility), and coinfection with ectoparasites such as sea lice Caligus rogercresseyi, may also influence disease onset and severity (Lhorente et al. 2014, Montory et al. 2018). Atlantic salmon infected with C. rogercresseyi have been reported to have reduced immunity to P. salmonis (Lhorente et al. 2014). Furthermore, sea lice have been reported to survive better at salinity > 20 PSU (Groner et al. 2016) and a significant association between the abundance of adult C. rogercresseyi and high mortality rates in salmon due to piscirickettsiosis has also been reported in Chilean farms (Arriagada et al. 2019).

The hydrodynamic model predictions showed that salinity and temperature vary considerably, both seasonally and among farms (Fig. 4). Sea surface temperature increases in summer in a north-east direction within the study area, while salinity increases in a south-east direction due to freshwater inflow from rivers and streams. Consequently, the risk of piscirickettsiosis associated with changes in temperature and salinity is expected to vary significantly throughout the year and across different locations in the Los Lagos region.

\subsection{Model limitations and future research}

In building the stochastic model, several assumptions were made. First, a homogeneous disease-state 
condition was assumed at the fish farms (i.e. all fish in the same disease state at the same time). The scale of disease outbreaks can range from single individuals in cages to the entire farm population over time. Second, for the sake of simplicity, covariates (the number of upstream infected farms, associated mortalities, temperature, and salinity) were assumed constant over the farming cycle. Third, we used piscirickettsiosis-induced mortality as a proxy for the pressure of infection from source farms ( $P$. salmonis shedding) assuming a $6 \mathrm{wk} w_{\text {max }}^{\prime}$. Potential bias associated with using mortality data as a surrogate of bacteria prevalence in water was offset by initiating particle release computational experiments $3 \mathrm{wk}$ prior to mortality being recorded at the farm to account for the incubation period of piscirickettsiosis. Finally, the particle model representing piscirickettsiosis survival in seawater assumed a constant exponential decay rate of $2.5 \mathrm{~d}$ ( $50 \%$ reduction in $\sim 0.25 \mathrm{~d}$ ) (Lannan \& Fryer 1994, Almendras \& Fuentealba 1997). This decay rate may be conservative, given more recent estimates of survival time as long as 8 wk by Olivares \& Marshall (2010) and S. A. Contreras-Lynch et al. (unpubl. data). The implications of longer survival time of $P$. salmonis in seawater are that the scales of connectivity among farms are possibly much larger than predicted by our model. This might explain the discrepancy in the observed infection rate of $\sim 70 \%$ in non-connected farms. The assumption of a constant decay rate of piscirickettsiosis in seawater may need to be reviewed, as new evidence shows that decay rates vary significantly with temperature and salinity (S. A. Contreras-Lynch et al. unpubl. data). Incorporation of environmental dependencies of decay rates into particle release experiments would further improve the representation of the hydrodynamic dispersion of piscirickettsiosis in seawater. Finally, the development of new risk metrics could explicitly account for pathogen concentrations in seawater and apply a minimum infectivity dose for the disease to occur. Such thresholds have been reported for fish diseases like infectious salmon anaemia (Raynard et al. 2001, McBeath et al. 2015), infectious pancreatic necrosis virus (Smail et al. 2006), and the amoebic gill disease (Morrison et al. 2004), but the information on the infectious dose and shedding rates for piscirickettsiosis are relatively unknown.

Despite some degree of uncertainty and the potential improvements that could be made with availability of new data, the developed model corresponds well with the recorded piscirickettsiosis dynamic data in the study area and therefore can be consid- ered robust. This model could be used to explore the likely success of interventions and risk mitigation measures aimed at reducing exposure to waterborne infections. Potential connectivity matrices calculated in this study allowed us to identify farms that are highly connected i.e. receiving and spreading infection from and to other sites (stepping stones); source of pathogens to surrounding farms (super-spreaders) at high risk of being infected (super-sinks); and those isolated from the network which show a very low incidence of piscirickettsiosis. The characterization of farms according to their behavior in a 2-dimensional space (source versus sink) can potentially improve disease management by allowing prioritized pathogen and parasite control efforts at high-risk farms.

As part of this research project, we have developed an interactive online application that simulates piscirickettsiosis dynamics at salmon farming sites in the Los Lagos region using the R package 'shiny' (https:// oa-csirochile.shinyapps.io/waterborne-srs-transmission-risk/); step-by-step instructions for using the application are provided. This web-based program allows users to investigate piscirickettsiosis dynamics as a function of oceanographic conditions, and is expected to support communication among academia, the public, and industry sectors.

\subsection{Conclusions}

Spatial planning and management tools can be effectively used to reduce disease risks in the absence of robust disease-specific information (Salama \& Murray 2011). The present study aimed to develop new risk prediction models that could underpin the development of better risk management plans such as the identification of areas of high disease risk and the development of disease management strategies. At a regional scale, the developed model can help in the identification and isolation of farms in high disease dissemination areas or the selection of new farm locations with low connectivity. This may also assist in the development of area-based disease control measures such as coordinated stocking, harvesting, and fallowing. In the event of disease outbreak, models can also help in the designation of quarantine zones based on connectivity criteria rather than distance. A farm-scale model could assist in determining the size and density of farms in an area with high connectivity, early detection of the disease on farms, and evaluation of disease management strategies such as drug treatment or early harvesting in the event of disease outbreaks. Collectively, the imple- 
mentation of improved risk mitigation strategies could lead to earlier control of disease outbreaks and reduced mortality.

Acknowledgements. This work was developed within the research program executed by the National Fisheries and Aquaculture Service of Chile (SERNAPESCA) Program for the Sanitary Management of Aquaculture (projects FIEV014 and FIE- 201707240090), funded through public and private arrangements between the Ministry of Economy, Development, and Tourism of Chile (Minecon) and the Association of the Chilean Salmon Industry AG (SalmonChile). We also gratefully acknowledge the novel and foundational dynamic modeling tools used and adapted here developed by Shane Richards of the University of Tasmania (epidemiology). We further thank the support and advice provided by Alfredo Lopez, Diego Ocampo, and Jonathan Hodge from CSIRO Chile.

\section{LITERATURE CITED}

Alaliyat S, Yndestad H, Davidsen PI (2019a) An agent-based approach for predicting patterns of pathogen transmission between aquaculture sites in the Norwegian fjords. Aquaculture 505:98-111

Alaliyat S, Yndestad H, Davidsen PI (2019b) Optimal fish densities and farm locations in Norwegian fjords: a framework to use a PSO algorithm to optimize an agentbased model to simulate fish disease dynamics. Aquacult Int 27:747-770

Aldrin M, Lyngstad TM, Kristoffersen AB, Storvik B, Borgan $\varnothing$, Jansen PA (2011) Modelling the spread of infectious salmon anaemia among salmon farms based on seaway distances between farms and genetic relationships between infectious salmon anaemia virus isolates. J R Soc Interface 8:1346-1356

Almendras FE, Fuentealba IC (1997) Salmonid rickettsial septicemia caused by Piscirickettsia salmonis: a review. Dis Aquat Org 29:137-144

*Almendras FE, Fuentealba IC, Jones SRM, Markham F, Spangler E (1997) Experimental infection and horizontal transmission of Piscirickettsia salmonis in freshwaterraised Atlantic salmon, Salmo salar L. J Fish Dis 20: $409-418$

Amundrud TL, Murray AG (2009) Modelling sea lice dispersion under varying environmental forcing in a Scottish sea loch. J Fish Dis 32:27-44

* Arriagada G, Hamilton-West C, Nekouei O, Foerster C, Müller A, Lara M, Gallardo-Escarate C (2019) Caligus rogercresseyi infestation is associated with Piscirickettsia salmonis-attributed mortalities in farmed salmonids in Chile. Prev Vet Med 171:104771

Cabezas M (2006) Fármacos naturales en el cultivo de Salmonídeos: una alternativa en el control de enfermedades. Salmociencia 1:27-33

Callaway R, Shinn AP, Grenfell SE, Bron JE and others (2012) Review of climate change impacts on marine aquaculture in the UK and Ireland. Aquat Conserv 22:389-421

Contreras-Lynch S, Olmos P, Vargas A, Figueroa J, GonzálezStegmaier R, Enríquez R, Romero A (2015) Identification and genetic characterization of Piscirickettsia salmonis in native fish from southern Chile. Dis Aquat Org 115: 233-244
Cusack RR, Groman DB, Jones SRM (2002) Rickettsial infection in farmed Atlantic salmon in eastern Canada. Can Vet J 43:435-440

* Cvitanich J, Garate NO, Smith C (1991) The isolation of a rickettsia-like organism causing disease and mortality in Chilean salmonids and its confirmation by Koch's postulate. J Fish Dis 14:121-145

Cvitanich J, Gárate O, Silva C, Andrade M, Figueroa C, Smith C (1995) Isolation of a new rickettsia-like organism from Atlantic salmon in Chile. American Fisheries Society/ Fish Health Section Newsletter 23(3):1-3

* Engering A, Hogerwerf L, Slingenbergh J (2013) Pathogenhost-environment interplay and disease emergence. Emerg Microbes Infect 2:e5

* Estévez RA, Mardones FO, Álamos F, Arriagada G and others (2019) Eliciting expert judgements to estimate risk and protective factors for piscirickettsiosis in Chilean salmon farming. Aquaculture 507:402-410

Figueroa J, Cárcamo J, Yañez A, Olavarria V and others (2019) Addressing viral and bacterial threats to salmon farming in Chile: historical contexts and perspectives for management and control. Rev Aquacult 11(Spec Issue): 299-324

Foreman MGG, Chandler PC, Stucchi DJ, Garver KA, Guo M, Morrison J, Tuele D (2015a) The ability of hydrodynamic models to inform decisions on the siting and management of aquaculture facilities in British Columbia. Can Sci Advis Sec Res Doc 2105/005. Fisheries and Oceans Canada, Ottawa

*Foreman MGG, Guo M, Garver KA, Stucchi D and others (2015b) Modelling infectious hematopoietic necrosis virus dispersion from marine salmon farms in the Discovery Islands, British Columbia, Canada. PLOS ONE 10: e0130951

*Fryer JL, Hedrick RP (2003) Piscirickettsia salmonis: a Gram-negative intracellular bacterial pathogen of fish. J Fish Dis 26:251-262

Garcés LH, Larenas JJ, Smith PA, Sandino S, Lannan CN, Fryer JL (1991) Infectivity of a rickettsia isolated from coho salmon Oncorhynchus kisutch. Dis Aquat Org 11:93-97

Groner ML, McEwan GF, Rees EE, Gettinby G, Revie CW (2016) Quantifying the influence of salinity and temperature on the population dynamics of a marine ectoparasite. Can J Fish Aquat Sci 73:1281-1291

*Gustafson LL, Ellis SK, Beattie MJ, Chang BD and others (2007) Hydrographics and the timing of infectious salmon anemia outbreaks among Atlantic salmon (Salmo salar L.) farms in the Quoddy region of Maine, USA and New Brunswick, Canada. Prev Vet Med 78:35-56

Herzfeld M (2006) An alternative coordinate system for solving finite difference ocean models. Ocean Model 14: 174-196

Herzfeld M (2018) SIMA Austral Hydrodynamic Model Technical Report. In: Steven A, Andrewartha J, Bernal P, Bravo F and others (eds) SIMA Austral. FIE V008 - Integrated Ecosystem-based Sanitary and Environmental Management System for Aquaculture. Final Report. CSIRO, Santiago, p 178

Jansen PA, Kristoffersen AB, Viljugrein H, Jimenez D, Aldrin M, Stien A (2012) Sea lice as a density-dependent constraint to salmonid farming. Proc R Soc B 279:2330-2338

Kristoffersen AB, Rees EE, Stryhn H, Ibarra R, Campisto JL, Revie CW, St-Hilaire S (2013) Understanding sources of sea lice for salmon farms in Chile. Prev Vet Med 111: $165-175$ 
Lannan CN, Fryer JL (1994) Extracellular survival of Piscirickettsia salmonis. J Fish Dis 17:545-548

Lhorente JP, Gallardo JA, Villanueva B, Carabaño MJ, Neira $R$ (2014) Disease resistance in Atlantic salmon (Salmo salar): coinfection of the intracellular bacterial pathogen Piscirickettsia salmonis and the sea louse Caligus rogercresseyi. PLOS ONE 9:e95397

Lyngstad TM, Jansen PA, Sindre H, Jonassen CM, Hjortaas MJ, Johnsen S, Brun E (2008) Epidemiological investigation of infectious salmon anaemia (ISA) outbreaks in Norway 2003-2005. Prev Vet Med 84:213-227

* Maisey K, Montero R, Christodoulides M (2017) Vaccines for piscirickettsiosis (salmonid rickettsial septicaemia, SRS): the Chile perspective. Expert Rev Vaccines 16: 215-228

Mardones FO, Perez AM, Valdes-Donoso P, Carpenter TE (2011) Farm-level reproduction number during an epidemic of infectious salmon anemia virus in southern Chile in 2007-2009. Prev Vet Med 102:175-184

Mardones FO, Paredes F, Medina M, Tello A and others (2018) Identification of research gaps for highly infectious diseases in aquaculture: the case of the endemic Piscirickettsia salmonis in the Chilean salmon farming industry. Aquaculture 482:211-220

McBeath A, Aamelfot M, Christiansen DH, Matejusova I and others (2015) Immersion challenge with low and highly virulent infectious salmon anaemia virus reveals different pathogenesis in Atlantic salmon, Salmo salar L. J Fish Dis 38:3-15

MINECOM (Ministerio de Economía, Fomento y Turismo) (2002) Decreto 319. Aprueba reglamento de medidas de proteccion, control y erradicacion de enfermedades de alto riesgo para las especies hidrobiologicas. Deroga decreto no 162, de 1985. www.subpesca.cl/portal/615/ w3-article-83903.html

Miranda CD, Godoy FA, Lee MR (2018) Current status of the use of antibiotics and the antimicrobial resistance in the Chilean salmon farms. Front Microbiol 9:1284

MODS (2012) Strømmodellering og smitte-spredning. https:// www.sintef.no/sinmod/\#/

Montory JA, Cumillaf JP, Cubillos VM, Paschke K, Urbina MA, Gebauer P (2018) Early development of the ectoparasite Caligus rogercresseyi under combined salinity and temperature gradients. Aquaculture 486:68-74

* Morrison RN, Crosbie PBB, Nowak BF (2004) The induction of laboratory-based amoebic gill disease revisited. J Fish Dis 27:445-449

Murray AG (2013) Epidemiology of the spread of viral diseases under aquaculture. Curr Opin Virol 3:74-78

* Murray AG, Gubbins M (2016) Spatial management measures for disease mitigation as practiced in Scottish aquaculture. Mar Policy 70:93-100

* Murray AG, Munro LA, Wallace IS, Berx B, Pendrey D, Fraser D, Raynard RS (2010) Epidemiological investigation into the re-emergence and control of an outbreak of infectious salmon anaemia in the Shetland Islands, Scotland. Dis Aquat Org 91:189-200

* Nepal S, Chen J, Penton DJ, Neumann LE, Zheng H, Wahid S (2017) Spatial GR4J conceptualization of the Tamor glaciated alpine catchment in Eastern Nepal: evaluation of GR4JSG against streamflow and MODIS snow extent. Hydrol Processes 31:51-68

Oke PR, Brassington GB, Griffin DA, Schiller A (2008) The Bluelink ocean data assimilation system (BODAS). Ocean Model 21:46-70
Olivares J, Marshall S (2010) Determination of minimal concentration of Piscirickettsia salmonis in water columns to establish a fallowing period in salmon farms. J Fish Dis 33:261-266

* Olsen AB, Melby HP, Speilberg L, Evensen $\varnothing$, Håstein T (1997) Piscirickettsia salmonis infection in Atlantic salmon Salmo salar in Norway-epidemiological, pathological and microbiological findings. Dis Aquat Org 31:35-48

* Perrin C, Michel C, Andréassian V (2003) Improvement of a parsimonious model for streamflow simulation. J Hydrol (Amst) 279:275-289

* Price D, Ibarra R, Sánchez J, St-Hilaire S (2017) A retrospective assessment of the effect of fallowing on piscirickettsiosis in Chile. Aquaculture 473:400-406

* Raynard RS, Snow M, Bruno DW (2001) Experimental infection models and susceptibility of Atlantic salmon Salmo salar to a Scottish isolate of infectious salmon anaemia virus. Dis Aquat Org 47:169-174

* Rees EE, Ibarra R, Medina M, Sanchez J, Jakob E, Vanderstichel R, St-Hilaire S (2014) Transmission of Piscirickettsia salmonis among salt water salmonid farms in Chile. Aquaculture 428-429:189-194

* Rivas-Aravena A, Sandino AM, Spencer E (2013) Nanoparticles and microparticles of polymers and polysaccharides to administer fish vaccines. Biol Res 46:407-419

Rozas M, Enriquez R (2014) Piscirickettsiosis and Piscirickettsia salmonis in fish: a review. J Fish Dis 37:163-188

* Salama NKG, Murray AG (2011) Farm size as a factor in hydrodynamic transmission of pathogens in aquaculture fish production. Aquacult Environ Interact 2:61-74

Salama NKG, Murray AG (2012) Fish farm size and surrounding water current speeds dictate the separation distance required to avoid transmission of disease agents between production sites. In: Proc SVEPM 2012, 28-30 March 2012, Glasgow. Society for Veterinary Epidemiology and Preventive Medicine, Glasgow, p 41-54

Salama NKG, Murray AG (2013) A comparison of modelling approaches to assess the transmission of pathogens between Scottish fish farms: the role of hydrodynamics and site biomass. Prev Vet Med 108:285-293

* Salama NKG, Rabe B (2013) Developing models for investigating the environmental transmission of diseasecausing agents within open-cage salmon aquaculture. Aquacult Environ Interact 4:91-115

Salama NKG, Murray AG, Rabe B (2011) Modelling dispersal of salmon lice in a large fjordic system: Loch Linnhe, Scotland. In: Chan F, Marinova D, Anderssen RS (eds) MODSIM2011: $19^{\text {th }}$ international congress on modelling and simulation, 12-16 December 2011, Perth. Modelling and Simulation Society of Australia and New Zealand, Canberra, p 2156-2162

* Salama NKG, Dale AG, Ivanov VV, Cook PF, Pert CC, Collins CM, Rabe B (2018) Using biological-physical modelling for informing sea lice dispersal in Loch Linnhe, Scotland. J Fish Dis 41:901-919

* Samsing F, Johnsen I, Stien LH, Oppedal F, Albretsen J, Asplin L, Dempster T (2016) Predicting the effectiveness of depth-based technologies to prevent salmon lice infection using a dispersal model. Prev Vet Med 129:48-57

* Samsing F, Johnsen I, Dempster T, Oppedal F, Treml EA (2017) Network analysis reveals strong seasonality in the dispersal of a marine parasite and identifies areas for coordinated management. Landsc Ecol 32:1953-1967

* Schulte PM (2015) The effects of temperature on aerobic metabolism: towards a mechanistic understanding of the 
responses of ectotherms to a changing environment. J Exp Biol 218:1856-1866

SERNAPESCA (Servicio Nacional de Pesca y Acuicultura) (2008) Resolución No 776 de 2008. Dispone medidas de contingencia ante brote de anemia infecciosa del salmón (ISA). www.sernapesca.cl/transparencia/normativa_a7g .html

SERNAPESCA (2009) Resolución No 1449 de 2009, Establece medidas de manejo sanitario por área. https://www. leychile.cl/Navegar?idNorma=1003741

SERNAPESCA (2016) Informe sanitario de salmonicultura en centros marinos año 2015. www.sernapesca.cl/sites/ default/files/informe_sanitario_2015.pdf

SERNAPESCA (2017a) Validadores de información productiva para centros de salmónidos de engorda en mar basado en el proyecto 'Consultoría para el apoyo en el desarrollo del proyecto sistema integrado de gestión sanitaria y ambiental para la acuicultura con foco en el mejoramiento de la captura, validación, monitoreo y análisis de información administrada en SERNAPESCA'. Ejecutado por la Fundación para la Transferencia Tecnológica (UNTEC), Santiago

SERNAPESCA (2017b) Validadores de información productiva para centros de salmónidos de engorda en mar basado en el proyecto 'Asesoría estratégica para el mejoramiento de la captura, validación y análisis de información administrada en SERNAPESCA a utilizar en los estudios epidemiológicos para SRS'. Ejecutado por la Fundación para la Transferencia Tecnológica (UNTEC), Santiago

SERNAPESCA (2018a) Anuario estadístico de pesca y acuicultura 2018. www.sernapesca.cl/informacion-utilidad/ anuarios-estadisticos-de-pesca-y-acuicultura\#

SERNAPESCA (2018b) Informe sanitario de salmonicultura en centros marinos año 2018. http://www.sernapesca.cl/ sites/default/files/informe_sanitario_salmonicultura_en_ centros_marinos_2018_final.pdf

SERNAPESCA (2018c) Informe sanitario de salmonicultura en centros marinos año 2017. www.sernapesca.cl/sites/ default/files/informe_sanitario_2017_0.pdf

SERNAPESCA (2018d) Programa sanitario general laboratorios de diagnóstico de enfermedades de animales acuáticos. Norma técnica No 1. Procedimientos para el muestreo de animales. www.sernapesca.cl/sites/default/ files/labd-nt1.pdf

Editorial responsibility: Megan La Peyre, Baton Rouge, Louisiana, USA
Smail DA, Bain N, Bruno DW, King JA and others (2006) Infectious pancreatic necrosis virus in Atlantic salmon, Salmo salar L., post-smolts in the Shetland Isles, Scotland: virus identification, histopathology, immunohistochemistry and genetic comparison with Scottish mainland isolates. J Fish Dis 29:31-41

Smith PA, Lannan CN, Garces LH, Jarpa M and others (1995) Piscirickettsiosis: a bacterin field trial in coho salmon (Onchorhynchus kisutch). Bull Eur Assoc Fish Pathol 15: 137-141

Smith PA, Pizarro P, Ojeda P, Contreras J, Oyanedel S, Larenas J (1999) Routes of entry of Piscirickettsia salmonis in rainbow trout Oncorhynchus mykiss. Dis Aquat Org 37 : 165-172

Smith PA, Rojas ME, Guajardo A, Contreras J, Morales MA, Larenas J (2004) Experimental infection of coho salmon Oncorhynchus kisutch by exposure of skin, gills and intestine with Piscirickettsia salmonis. Dis Aquat Org 61: 53-57

* Stene A, Bang Jensen B, Knutsen Ø, Olsen A, Viljugrein H (2014a) Seasonal increase in sea temperature triggers pancreas disease outbreaks in Norwegian salmon farms. J Fish Dis 37:739-751

Stene A, Viljugrein H, Yndestad H, Tavornpanich S, Skjerve E (2014b) Transmission dynamics of pancreas disease (PD) in a Norwegian fjord: aspects of water transport, contact networks and infection pressure among salmon farms. J Fish Dis 37:123-134

Steven AD, Aryal S, Bernal P, Bravo F and others (2019) SIMA Austral: an operational information system for managing the Chilean aquaculture industry with international application. J Oper Oceanogr 12(Suppl 2):S29-S46

Stevenson M, Nunes T, Sanchez J, Thornton R, Reiczigel J, Robison-Cox J, Sebastiani P (2013) epiR: an R package for the analysis of epidemiological data. $\mathrm{R}$ package version 09-43

Valenzuela $B$, Imarai $M$, Catalán $R$, Parra $M$ and others (2015) Evaluation of the bactericidal activity of secondary metabolites isolated from Heliotropium genus against Piscirickettsia salmonis. Boletín Latinoamericano y del Caribe de Plantas Medicinales y Aromáticas 14:131-140

Viljugrein H, Staalstrøm A, Molvær J, Urke HA, Jansen PA (2009) Integration of hydrodynamics into a statistical model on the spread of pancreas disease (PD) in salmon farming. Dis Aquat Org 88:35-44

Submitted: March 19, 2020; Accepted: June 3, 2020

Proofs received from author(s): July 8, 2020 